\title{
POETRY
}

\section{Year one}

\section{Dissection}

Today, I held your heart and wondered at its reflection in my chest.

How "naked" cannot describe the naked you are

because shame does not penetrate beneath the skin.

There will be nothing left of you except the relationships in my head: your nerves, muscle, and blood

leaving nothing of me except pieces of what I thought I am.

\section{aphasia}

1

so close

to what i want

to say

like on the tip of

the tip

of someone else's tongue.

2

from the fish bowl

i see your lips

move back and forth

back and forth

but on the surface

not a single wave.

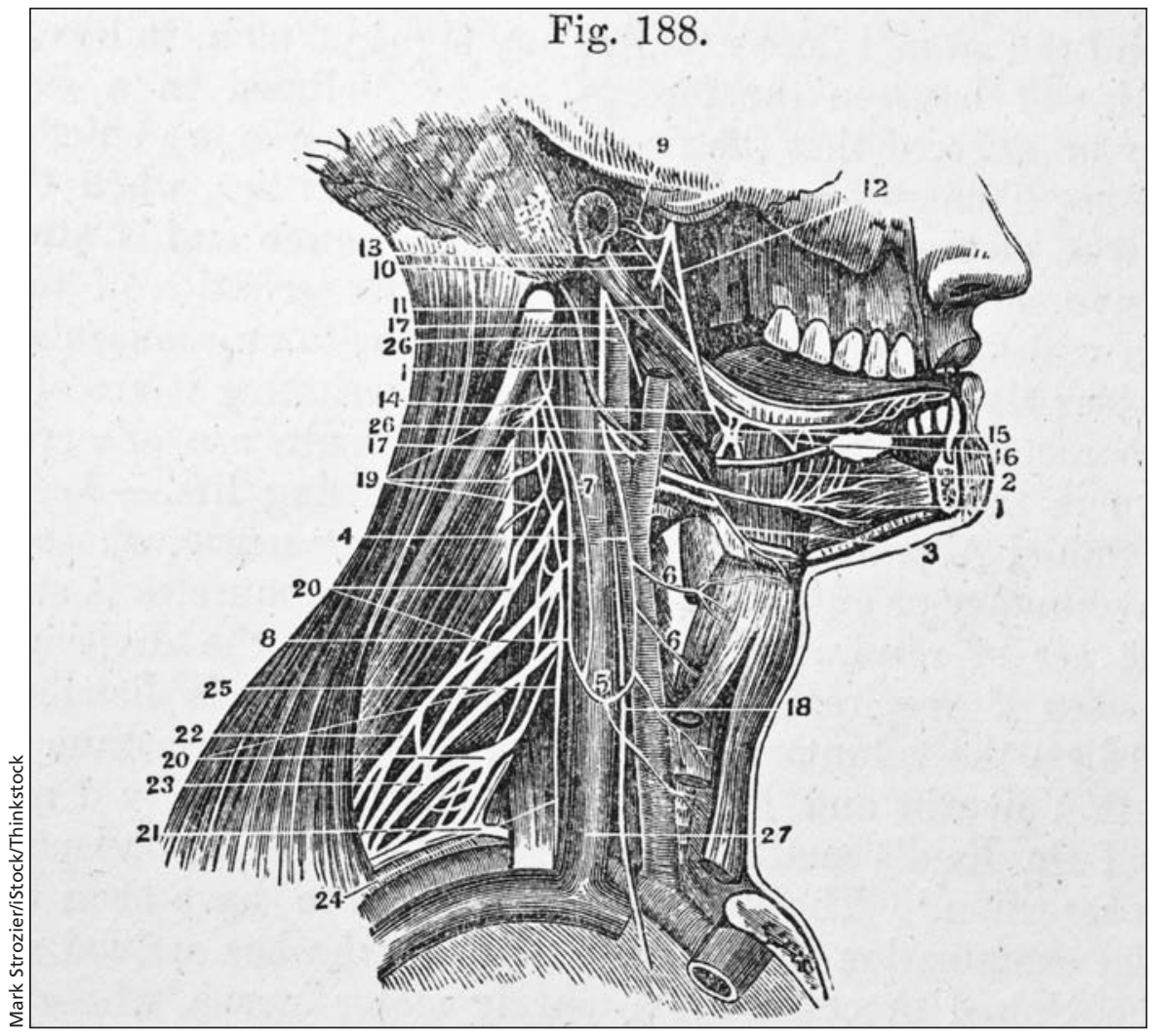

\section{Gastrointestinal physiology}

Already, I have forgotten the enzymes and pathways like the names of summer camp friends

or the film that stars that one guy.

Now, all I can recall

is when you open your mouth there is a hole that leads straight through you.

\section{Delivery}

Your first breath starts the drowning.

As pressure builds to close the heart.

Look! First, we judge you.

On a scale of one to ten we teach these life lessons:

More is better

but it's best to come out screaming.

Steven Dondlinger

CMAJ 2014. DOI:10.1503/cmaj.130928 